\section{The mackerel experiment}

CAltech opened its doors on 2 November 1891, when a man named Amos G. Throop decided to do something more interesting after lunch than plant potatoes. Instead, he founded a school of arts and crafts. The story could have ended then and there but for the arrival, in 1907 , of a new member of the board of trustees: the astronomer, George Ellery Hale. In 1903, Hale came to Pasadena from the University of Chicago, to look for somewhere to put his 60-inch telescope. He settled on nearby Mount Wilson.

By 1920 he had persuaded chemist Arthur Noyes (former president of MIT, the Massachusetts Institute of Technology) and physicist Robert Millikan (Professor of Physics at the University of Chicago, Hale's old school) to help him transform Throop into MIT on the West Coast. In 1920, Throop became the California Institute of Technology.

Today, the professorial faculty is around 300 , with around 1,100 graduate students and 900 undergraduates. Like the Salk, it has remained small by choice. measure. paid in the country.
This policy has worked, if the large number of Caltech Nobel Laureates (21) is a

About half its \$253-million budget comes from federal sources directly. The other half comes from industrial support, channelled through Caltech's Office of Sponsored Research (OSR). Like the Salk, Caltech takes a tough line to preserve its independence, and insists that the publication of industrially sponsored research is not delayed by patent review. But Caltech has been running for three times longer than the Salk and has, therefore, had the chance to accrete an endowment of $\$ 580$ million. The faculty of this private school is among the best

It hasn't always been such a bed of roses. For example, it is hard to understand, when women had attended Throop from the first, why Caltech decided to bar them after after 1910. Another 60 years were to pass before that policy was revoked. It is even harder to understand why, in what must rank as one of Caltech's lesser known achieve-

ments, the Class of 1937 sought to discover the distance between Caltech and Pasadena City Hall in terms of the number of mackerel, laid end to end $(5,678)$. In current circumstances, though, it is easier to understand why, in the Depression, Millikan (by then the Chairman of Caltech's Executive Council) asked faculty to take a salary cut of 10 per cent twice that faced by UC faculty today. (They agreed.)

Such events though, account for Caltech's character, typified by an initiative that stands somewhere between what staid folk would consider possible, and the mackerel experiment: that is, LIGO - the Laser Interferometer Gravitational-Wave Observatory (see photo), a collaboration between Caltech and MIT. LIGO is designed to observe cosmic events inaccessible to the electromagnetic spectrum, such as the effect of supernovae and black holes on the spacetime continuum.

The director of the LIGO project is Rochus "Robbie" Vogt, professor of physics and a member of the faculty for more than
30 years. Vogt's scientific team currently consists of about 40 people at Caltech and MIT, and construction has begun at the two sites. One is a former nuclear reservation in Washington State, the other is near Baton Rouge, Louisiana. By the time it is finished, LIGO will have cost about $\$ 250$ million: the NSF has granted $\$ 19.1$ million for the initial design and evaluation phases, and at the time of writing Vogt awaits another tranche of a similar amount, so the bulldozers can move in.

Importantly, LIGO only seems like "Big Science" (on a CERN or SSC scale) because of the immense technical problems involved. But these are of such consequence that, for LIGO to work at all, the team must be small enough for each member to have a good idea of what everyone else is doing. "It is vitally important that the LIGO team be a tightly knit, fully integrated and rather Renaissance kind of team," says Vogt, "where everybody is strong in something but knowledgeable in everything else. This is a fun project for a physicist."

\section{LAWRENCE LIVERMORE -}

\section{Beating around the bomb}

ARRIVE as early as possible at a nuclear weapons laboratory. The time saved is useful for delays in the Pass Office. But after the required picture-taking and form-filling, I held the door open for a party of entering Russians. Such is the change at the Lawrence Livermore National Laboratory (LLNL).

Originally meant to service a programme of research into nuclear weapons and thermonuclear fusion, the laboratory has branched into almost every kind of applied science, and weapons research now accounts for less than 30 per cent. Environmental sciences, in contrast, has grown by 50 per cent per year, from about $\$ 25$ million annually in the late 1980 s to almost $\$ 200$ million today.

Livermore was founded by Edward $\mathrm{O}$. Lawrence in 1952 as a rival to the Los Alamos National Laboratory in New Mexico, which had been set up in 1943 as part of the Manhattan Project. The University of California administers both, as well as the smaller Lawrence Berkeley Laboratory, on behalf of the Department of Energy. LLNL is the largest of the three, and consumes slightly more than half their combined budget of $\$ 2.5$ billion.

Most of the civil research here can trace its roots, ultimately, to the weapons programme or to the originally small component of the programme devoted to fusion energy research. Deeper still lies Lawrence's conception, that scientists detected by one of them comes from space, and is not the result of local disturbances such as small earthquakes. 